\title{
An Overview on the Role of Relative Humidity in Airborne Transmission of SARS-CoV-2 in Indoor Environments
}

\author{
Ajit Ahlawat $^{1 *}$, Alfred Wiedensohler ${ }^{1}$, Sumit Kumar Mishra ${ }^{2}$ \\ ${ }^{1}$ Leibniz Institute for Tropospheric Research (TROPOS), Permoserstraße, 15 Leipzig, Germany \\ ${ }^{2}$ CSIR-National Physical Laboratory, New Delhi, India
}

\begin{abstract}
COVID-19 disease is caused by severe acute respiratory syndrome coronavirus 2 (SARS-CoV-2), which originated in Wuhan, China and spread with an astonishing rate across the world. The transmission routes of SARS-CoV-2 are still debated, but recent evidence strongly suggests that COVID-19 could be transmitted via air in poorly ventilated places. Some studies also suggest the higher surface stability of SARS-CoV-2 as compared to SARS-CoV-1. It is also possible that small viral particles may enter into indoor environments from the various emission sources aided by environmental factors such as relative humidity, wind speed, temperature, thus representing a type of an aerosol transmission. Here, we explore the role of relative humidity in airborne transmission of SARS-CoV-2 virus in indoor environments based on recent studies around the world. Humidity affects both the evaporation kinematics and particle growth. In dry indoor places i.e., less humidity $(<40 \% \mathrm{RH})$, the chances of airborne transmission of SARS-CoV-2 are higher than that of humid places (i.e., $>90 \% \mathrm{RH})$. Based on earlier studies, a relative humidity of 40-60\% was found to be optimal for human health in indoor places. Thus, it is extremely important to set a minimum relative humidity standard for indoor environments such as hospitals, offices and public transports for minimization of airborne spread of SARS-CoV-2.
\end{abstract}

Keywords: Aerosol; COVID-19; SARS-CoV-2; Indoor; Humidity.

\section{INTRODUCTION}

The World Health Organization (WHO) declared a global pandemic for the outbreak of novel coronavirus disease (nCOVID-19), which is a highly transmittable and pathogenic viral infection caused by severe acute respiratory syndrome coronavirus 2 (SARS-CoV-2) (Sanders et al., 2020; WHO, 2020b). There are more than 7 million confirmed COVID-19 cases worldwide through June 10, 2020 (Worldometer, 2020) since its first reported case in Wuhan, China in December, 2019 (WHO, 2020a). The overall geographic range of COVID-19 spread is much larger as compared with the epidemic of the severe acute respiratory syndrome (SARS) in 2003 (WHO, 2004). SARS-CoV-2 is identified as an enveloped, non-segmented, positive ribonucleic acid (RNA) virus with a diameter of $65-125 \mathrm{~nm}$, containing single strands of RNA with spikes in a crown shape on the outer surfaces (Astuti and Ysrafil, 2020). SARS-CoV-2 is majorly transmitted from human-to-human via direct or indirect contact between people and with contaminated surfaces

\footnotetext{
* Corresponding author.

Tel.: +49-163-3019-921

E-mail address: ahlawat@tropos.de
}

(Prather et al., 2020). It is clear that airborne transmission of SARS-CoV-2 is likely although many countries have not acknowledged this possibility (Tellier et al., 2019; Asadi et al., 2020; Hadei et al., 2020; Hsiao et al., 2020; Morawska and Cao, 2020; National Academies of Sciences, Engineering, and Medicine, 2020; Prather et al., 2020; Setti et al., 2020; van Doremalen et al., 2020). Similarly, Paules et al. (2020) recently pointed out that the airborne transmission of SARSCOV-2 may also occur besides close distance contacts. Recently, SARS-CoV-2 was found in aerosols in the hospitals in Wuhan, China farther than $6 \mathrm{ft}$. distance (Liu et al., 2020). Generally, respiratory infections occur through the transmission of aerosols $(<5 \mu \mathrm{m})$ and viral droplets (> 5-10 $\mu \mathrm{m}$ ) exhaled from the infected persons. The larger respiratory viral droplets will fall due to gravitational settling, which leads to contact transmission, whereas smaller droplets will lose mass through evaporation and remain in the air for a longer time (Prather et al., 2020). It has been shown in a recent study that small droplets of radius approx. $5 \mu \mathrm{m}$ will take 9 minutes to reach the ground when produced at height of $160 \mathrm{~cm}$ i.e., average speaking height. These small droplets are of specific interest because of their association with aerosol transmission of SARS-CoV-2 (Somsen et al., 2020). These exhaled droplets are basically dilute saline solutions with salts, water and some organics material along with the attached virus (Kumar and Morawska, 2020). The 
large population of these fine droplets originating from coughing, sneezing and speech remain airborne for many hours and can infect healthy persons (Prather et al., 2020). The coronavirus transmission can also be affected by various factors such as climate conditions (majorly temperature, humidity and wind speed), population density, available medical facilities (Dalziel et al., 2018). It is shown in previous studies that wintertime climate and host behavior can favor the influenza transmission (Shaman et al., 2011; Chattopadhyay et al., 2018) and other human coronaviruses (Killerby et al., 2018; Neher et al., 2020). Current studies indicate that temperature and humidity have a significant influence on the number of confirmed cases for a certain location (Bukhari and Jameel, 2020). Therefore, precise understanding of the influence of humidity on the transmissibility of COVID-19 in indoor environments is important for general public awareness. For indoor areas with poor ventilation facilities, people inhale the recirculating air. In cold and temperate climates, within an indoor environment, the RH values are typically low. Due to low RH, the droplets will evaporate at a more rapid rate forming particles with smaller sizes (Feng et al., 2020). The smaller size could lead to more airborne suspension time of viral droplets and ultimately, they could be transported to farther distances depending on ventilation conditions (Bourouiba, 2020). But, in humid places, as the humidity increases, the viral droplet size increases and falls from the air faster providing less chances for other people to breathe in the infectious viral droplets. The role of humidity seems to be extremely important to the airborne spread of COVID-19 in indoor environments.

\section{ROLE OF RELATIVE HUMIDITY IN AIRBORNE TRANSMISSION OF SARS-COV-2 IN INDOOR CONDITIONS}

As the exhaled droplets comes out from an infected person, they will start either evaporating or there will be some droplet growth. Both these scenarios are relative humidity dependent (Feng et al., 2020). In dry indoor conditions, when the aerosol droplets containing viruses and other fluids are expelled in the air, they evaporate so that the water vapor pressure at aerosol surface equilibrates with the ambient conditions. The resulting water loss causes change in solute concentration like proteins, salts or changes in other properties such as pH (Marr et al., 2019). After evaporation of water, the microdroplets will become quite small and suspended in the air for longer durations. After some time, the suspended viral particles concentration will increase depending on the stagnant air and poor ventilation facilities, thus increasing the infection risk in public places such as hospitals, restaurants (Kumar and Morawska, 2020).

Based on literature, we have found that there are three different scenarios where RH affects virus transmission in the indoor surroundings (a) fate of microorganisms inside the viral droplets (b) survival or inactivation of virus on surfaces (c) role of dry indoor air in airborne transmission of viruses.

\section{Fate of Microorganisms inside the Viral Droplets}

Highly infectious diseases transmission such as COVID-19 requires pathogens to remain active outside of the host body. $\mathrm{RH}$ affects the survival of some of these microorganisms in the environment. A recent study explained that the viruses survived well at RHs below $33 \%$ and at $100 \%$, whereas, at the intermediate RHs the viability was considerably reduced (Lin and Marr, 2020). Lin and Marr (2020) investigated the effect of RH on the viability of viruses both in suspended aerosols and in droplets using culture-based approaches. Based on the Lin and Marr (2020) findings, the viability is typically much lower at a $\mathrm{RH}$ around $60 \%(\sim 55 \%)$. This is because evaporation kinetics plays an important role in modulating the survival of the microorganism within the droplets or aerosols. RH controls the evaporation kinetics of the droplets. The enrichment factor (i.e., the calculated concentration of the solute given a certain amount of water loss or the fold increase in concentration of the solutes, as the droplets evaporate) is an important parameter while explaining the evaporation kinetics process. At lower RH, i.e., at $43 \%$ and below, Lin and Marr (2020) found the enrichment factor could increase rapidly with droplet evaporation and dry out completely, while at higher $\mathrm{RH}$, evaporation occurred more slowly leading to a gradual increase in the enrichment factor and the droplet never drying out. Lin and Marr (2020) characterized the impact of this evaporation with concentrations of solutes harmful to virus viability (e.g., salts) by calculating their cumulative dose, or sum of the products of the solute concentration and time. At lower RH, due to rapid evaporation, solute concentrations increased but then became irrelevant after the droplets dried out, allowing virus viability to remain high. At the highest $\mathrm{RH}$ levels, the cumulative dose increased slowly and did not greatly impact virus viability, while at intermediate $\mathrm{RH}$, cumulative dose was a crucial factor to reduce virus viability as the solute concentrations significantly increased while the droplet never completely evaporated. Thus, virus inactivation within droplets or aerosols is linked to the cumulative dose of a harmful substance in solution, which itself has a nonlinear response to $\mathrm{RH}$.

\section{Survival or Inactivation of Virus on Surfaces}

A report based on humidity's role on virus survival and inactivation on surfaces showed that high temperature at high relative humidity has a collegial impact on inactivation of SARS-CoV-1 viability (Chan et al., 2011). Whereas, lower temperatures and low humidity support prolonged survival of virus on contaminated surfaces. Another important point to mention here is that, the virus transmission has often occurred in well air-conditioned environments such as hospitals or hotels in some countries which has intensive use of air-conditioning (Chan et al., 2011).

\section{The Role of Dry Indoor Air in Airborne Transmission of Viruses}

There is a significant contribution of dry indoor air in both disease transmission and poor resident health. During cold winters, an outdoor air is drawn indoors and then heated to a comfortable temperature level. This process will significantly lower the indoor RH, which creates an extremely dangerous situation for indoor residents, particularly during the 
COVID-19 pandemic. When the indoor RH is less than 40 percent, humans becomes more vulnerable to viral respiratory infections making SARS-CoV-2 virus more infectious in the inhaled air. Earlier studies have shown that for human health, a relative humidity between 40 to $60 \%$ is optimum (Condair Ltd., 2007). When the indoor RH is lower than 40 percent, the resulting moisture-free air yields optimal route for long distance transmission of small infectious aerosols. These viral airborne particles will further travel, become inhaled by other residents, or finally settle on surfaces where they can survive for many days. The infectivity of many viruses, including SARS-CoV-2 are actually enhanced due to low RH levels. Dry air also causes a significant impact on our respiratory immunity. During the inhalation of low RH air, the mucus in our nose and throat becomes dry and more viscous, which diminish cilia's capability to expel viral aerosols. The low $\mathrm{RH}$ compromises the immune system's ability to effectively respond to microorganisms (Taylor, 2020). Human ear, nose and throat areas are more effective as virus fighter at high $\mathrm{RH}$ values rather than when room air is very dry (Hohmann-Jeddi, 2019). While social distancing reduces the risk of getting COVID-19 from other inhabitants through short range contamination by large droplets, it does less to prevent the transmission of tiny infectious aerosols in the air.

\section{COMPARISON OF INDOOR AND OUTDOOR (AMBIENT) RH RELATIONSHIP WITH COVID-19}

A quick comparison based on recent literature between indoor and outdoor (ambient) RH relationship with COVID-19 will provide more insights into this topic. An indoor environment is a microenvironment in which most people spend the major portion of their daily life. As a result, indoor air contributes to population exposures more than those outdoors, although of course being influenced by factors present at indoors as well as outdoors. In dry indoor places i.e., less humidity $(<40 \%)$, the chances of airborne transmission of COVID-19 are high. Based on an indoor experiment from Chinese cities during Jan-March 2020, the airborne spread of SARS-CoV-2 was reduced by increasing RH from $23.33 \%$ to $82.67 \%$ (Yao et al., 2020). Feng et al. (2020) recently investigated the influence of $\mathrm{RH}$ using numerical modeling. In the study, they considered $40 \% \mathrm{RH}$ as lower bound and $95 \% \mathrm{RH}$ as upper bound. They found that $40 \%$ $\mathrm{RH}$ activates the evaporation of water in the cough droplets, leading to droplet shrinkage and prolonged suspension in air whereas high RH at $95 \%$ will increase the droplet size due to hygroscopic growth with higher deposition fractions both on humans and on ground. Biktasheva (2020) emphasized on the air humidity control for indoor environment as a feasible way to mitigate patients' SARS-CoV-2 exposure. When considering ambient air humidity, an important role of humidity was found in rapid transmission of COVID-19 within the New York city (Bashir et al., 2020). Pani et al. (2020) found the positive correlation of absolute humidity (AH) with COVID-19 spread based on the daily data provided by Ministry of Health, Singapore. Similarly, a positive correlation was found between COVID-19 and RH $(r=0.106, p=0.001)$ in Kuala Lumpur, Malaysia (Suhaimi et al., 2020). Because, in more humid outdoor environments, the population is more likely to use drier indoor air and thus promote more COVID viability. Considering outdoor absolute humidity factor during cold winters, it was found that $73 \%$ of confirmed cases in region of study with $\mathrm{AH}$ in range $3-10 \mathrm{~g} \mathrm{~m}^{-3}$ (Huang et al., 2020). When the outdoor temperature is low and the indoor environment is heated, indoor RH is closely correlated with outdoor AH, resulting in more COVID-19 cases. Another study pointed out that COVID-19 spread was found to be significant in US with AH in range 4-6 $\mathrm{g} \mathrm{m}^{-3}$ (Gupta et al., 2020).

For better understanding, Table 1 depicts the influence of RH on the survival, transmission and infection of H1N1, SARS-CoV-1, MERS and SARS-CoV-2 viruses.

\section{POLICIES FOR CONTROLLING THE OUTBREAK OF SARS-COV-2 INCLUDING THE RH FACTOR}

Nowadays, there is an immense need for rapid development of effective vaccination and anti-viral medications which will save humanity from a brutal pandemic. But, apart from that, the building supervisors and government officials to play an extremely important role in reducing the viral transmission of these deadly diseases, such as SARS-CoV-2, by issuing guidelines and standards. Governments around the world have already set some indoor air quality standards for temperature and indoor pollutants, but to the best of our knowledge there are no such regulations and policies worldwide that require a minimum RH standard in public buildings and indoor environments. Based on research findings, for future scenarios, setting a minimum RH standard of $40 \%$ for public buildings will not only reduce the impact of COVID-19, but it will also reduce the impact of further viral outbreaks, both seasonal and novel. Though it is not an easy task to predict the outbreaks of viral infections, gathering enough knowledge on how these viral infections spread and developing counter plans accordingly will certainly prevent us from such large-scale pandemic like SARS-CoV-2. For countries in colder climates, minimum RH standard for the indoor environments should be kept into consideration. While, for tropical and typical hot countries, humidity control measures are recommended while avoiding extreme cooling of indoor places. Hygroscopic growth at high RH will play an important role in reducing the airborne spread of virus. Although virus viability will not be minimized at high $\mathrm{RH}$, the large droplet size will ensure the of being airborne is minimized. Overall, air humidifying is advised.

In order to implement the abovementioned guidelines, we need a concrete plan along with the relationship between different communities such as medical professionals, policy makers, planners and government officials. In order to curb the disease outbreaks, we must focus on the role of indoor air on disease transmission and resident health. Other precautions apart from RH optimization is to increase natural ventilations like opening of windows during indoor stay, using proper face masks (face shields along with face mask could provide better results), avoid staying in direct periphery of the infected or other persons, and maintaining social distancing. 


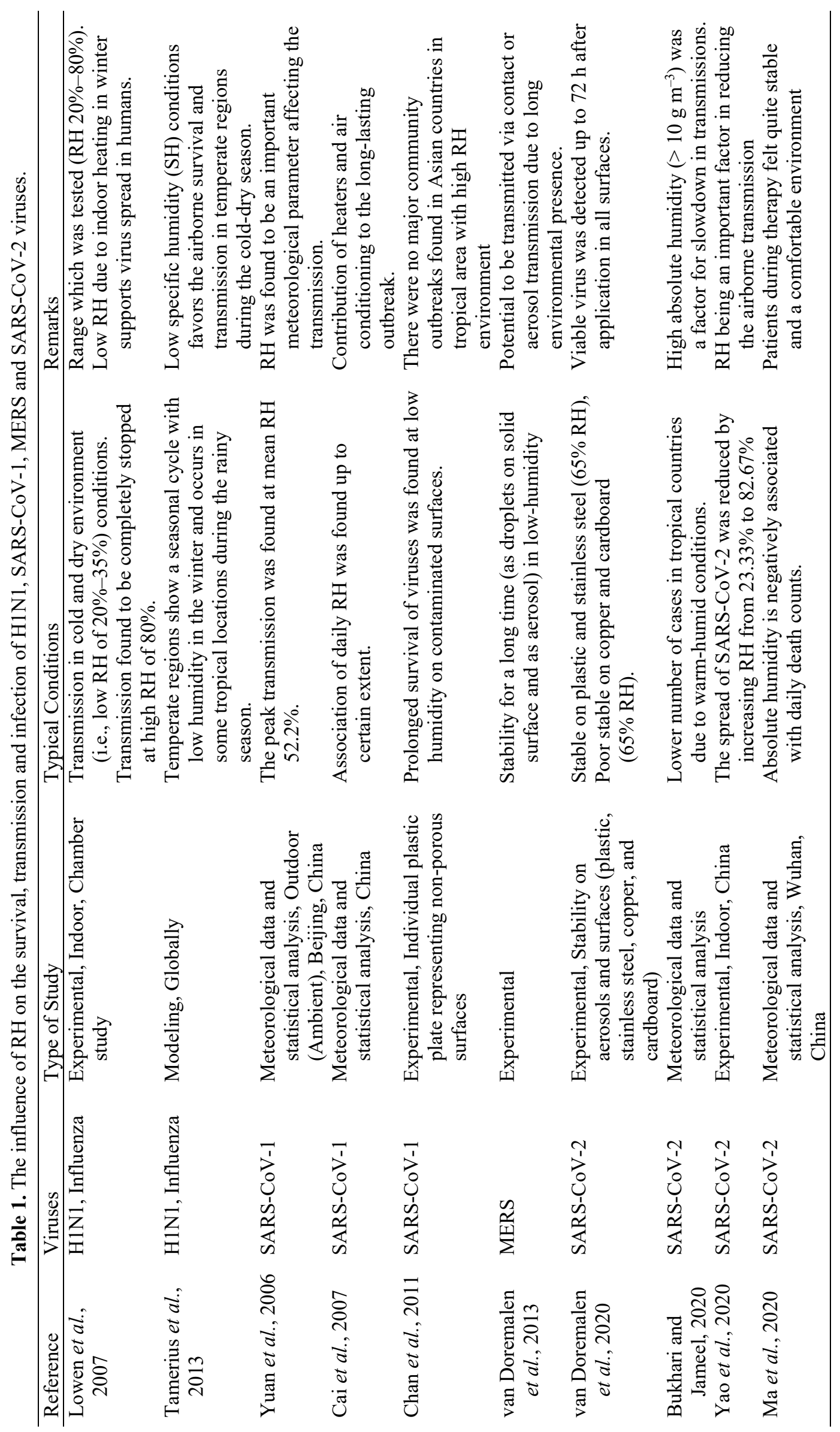




\section{ACKNOWLEDGEMENTS}

The authors confirm that no funding was received for this work. The authors declare that there are no competing interests.

\section{REFERENCES}

Asadi, S., Bouvier, N., Wexler, A.S. and Ristenpart, W.D. (2020). The coronavirus pandemic and aerosols: Does COVID-19 transmit via expiratory particles? Aerosol Sci. Technol. 54: 635-638. https://doi.org/10.1080/02786826. 2020.1749229

Astuti, I. and Ysrafil (2020). Severe Acute Respiratory Syndrome Coronavirus 2 (SARS-CoV-2): An overview of viral structure and host response. Diabetes Metab. Synd. 14: 407-412. https://doi.org/10.1016/j.dsx.2020.04.020

Bashir, M.F., Ma, B., Bilal., Komal, B., Bashir, M.A., Tan, D. and Bashir, M. (2020). Correlation between climate indicators and COVID-19 pandemic in New York, USA. Sci. Total Environ. 728: 138835. https://doi.org/10.1016/ j.scitotenv.2020.138835

Biktasheva, I.V. (2020). Role of habitat's air humidity in COVID-19 mortality. Sci. Total Environ. 736: 138763. https://doi.org/10.1016/j.scitotenv.2020.138763

Bourouiba, L. (2020). Turbulent gas clouds and respiratory pathogen emissions: Potential implications for reducing transmission of COVID-19. JAMA 323: 1837-1838. https://doi.org/10.1001/jama.2020.4756

Bukhari, Q. and Jameel, Y. (2020). Will coronavirus pandemic diminish by summer? SSRN 3556998. https://doi.org/10.2 139/ssrn.3556998

Cai, Q.C., Lu, J. and Xu, Q.F. (2007). Influence of meteorological factors and air pollution on the outbreak of severe acute respiratory syndrome. Public Health 121: 258-265. https://doi.org/10.1016/j.puhe.2006.09.023

Chan, K.H., Malik Peiris, J.S., Lam, S.Y., Poon, L.L.M., Yuen, K.Y. and Seto, W.H. (2011). The effects of temperature and relative humidity on the viability of the SARS coronavirus. Adv. Virol. 2011: 734690. https://doi.org/10.1155/2011/734690

Chattopadhyay, I., Kiciman, E., Elliott, J.W., Shaman, J.L. and Rzhetsky, A. (2018). Conjunction of factors triggering waves of seasonal influenza. eLife 7: e30756. https://doi.org/10.7554/eLife.30756

Condair Ltd. (2007). Healthy air humidity. The importance of air humidification in hospitals and in outpatient settings. https://www.condair.com/m/0/importance-of-health-airhumidity-in-hospitals-1.pdf

Dalziel, B.D., Kissler, S., Gog, J.R., Viboud, C., Bjornstad, O.N., Metcalfe, C.J.E. and Grenfell, B.T. (2018). Urbanization and humidity shape the intensity of influenza epidemics in US cities. Science 362:75-79. https://doi.org/10.1126/science.aat6030

Feng, Y., Marchal, T., Sperry, T. and Yi, H. (2020). Influence of wind and relative humidity on the social distancing effectiveness to prevent COVID-19 airborne transmission: A numerical study. J. Aerosol Sci. 147: 105585. https://doi.org/10.1016/j.jaerosci.2020.105585
Gupta, S., Raghuwanshi, G.S. and Chanda, A. (2020). Effect of weather on COVID-19 spread in the US: A prediction model for India in 2020. Sci. Total Environ. 728: 138860. https://doi.org/10.1016/j.scitotenv.2020.138860

Hadei, M., Hopke, P.K., Jonidi, A. and Shahsavani, A. (2020). A letter about the airborne transmission of SARSCoV-2 based on the current evidence. Aerosol Air Qual. Res. 20: 911-914. https://doi.org/10.4209/aaqr.2020.04.0 158

Hohmann-Jeddi, C. (2019, May 17). Dry air promotes infections. https://www.pharmazeutische-zeitung.de/trock ene-luft-foerdert-infektionen/

Hsiao, T.C., Chuang, H.C., Griffith, S.M., Chen, S.J. and Young, L. (2020). COVID-19: An aerosol's point of view expiration to transmission to viral mechanism. Aerosol Air Qual. Res. 20: 905-910. https://doi.org/10.4209/aaqr. 2020.04.0154

Huang, Z., Huang, J., Gu, Q., Du, P., Liang, H. and Dong, Q. (2020). Optimal temperature zone for the disposal of COVID-19. Sci. Total Environ. 736: 139487. https://doi.org/10.1016/j.scitotenv.2020.139487

Killerby, M.E., Biggs, H.M., Haynes, A., Dahl, R.M., Mustaquim, D., Gerber, S.I. and Watson, J.T. (2018). Human coronavirus circulation in the United States 20142017. J. Clin. Virol. 101: 52-56. https://doi.org/10.1016/ j.jcv.2018.01.019

Kumar, P. and Morawska, L. (2020). Could fighting airborne transmission be the next line of defence against COVID-19 spread? City Environ. Interact. 4: 100033. https://doi.org/10.1016/j.cacint.2020.100033

Lin, K. and Marr, L.C. (2020). Humidity-dependent decay of viruses, but not bacteria, in aerosols and droplets follows disinfection kinetics. Environ. Sci. Technol. 54: 1024-1032. https://doi.org/10.1021/acs.est.9b04959

Liu, Y., Ning, Z., Chen, Y., Guo, M., Liu, Y., Gali, N.K., Sun, L., Duan, Y., Cai, J., Westerdahl, D., Liu, X., Ho, K.F., Kan, H., Fu, Q. and Lan, K. (2020). Aerodynamic characteristics and RNA concentration of SARS-CoV-2 aerosol in Wuhan Hospitals during COVID-19 outbreak. Nature 582: 557-560. https://doi.org/10.1038/s41586020-2271-3

Lowen, A.C., Mubareka, S., Steel, J. and Palese, P. (2007). Influenza virus transmission is de-pendent on relative humidity and temperature. PLoS Pathog. 3: 151. https://doi.org/10.1371/journal.ppat.003015

Ma, Y., Zhao, Y., Liu, J., He, X., Wang, B., Fu, S., Yan, J., Niu, J., Zhou, J. and Luo, B. (2020). Effects of temperature variation and humidity on the death of COVID-19 in Wuhan, China. Sci. Total Environ. 724: 138226. https://doi.org/10.1016/j.scitotenv.2020.138226

Marr, L.C., Tang, J.W., Van Mullekom, J. and Lakdawala, S.S. (2019). Mechanistic insights into the effect of humidity on airborne influenza virus survival, transmission and incidence. J. R. Soc. Interface 16: 20180298. https://doi.org/10.1098/rsif.2018.0298

Morawska, L. and Cao, J. (2020). Airborne transmission of SARS-CoV-2: The world should face the reality. Environ. Int. 139: 105730. https://doi.org/10.1016/j.envint.2020.1 05730 
National Academies of Sciences, Engineering, and Medicine (2020). Rapid expert consultation on the possibility of bioaerosol spread of SARS-CoV-2 for the COVID-19 pandemic (April 1, 2020). The National Academies Press, Washington, DC. https://doi.org/10.17 226/25769

Neher, R.A., Dyrdak, R., Druelle, V., Hodcroft, E.B. and Albert, J. (2020). Potential impact of seasonal forcing on a SARS-CoV-2 pandemic. Swiss Med. Wkly. 150: w20224. https://doi.org/10.4414/smw.2020.20224

Pani, S.K., Lin, N.H. and RavindraBabu, S. (2020). Association of COVID-19 pandemic with meteorological parameters over Singapore. Sci. Total Environ. 740: 140112. https://doi.org/10.1016/j.scitotenv.2020.140112

Paules, C.I., Marston, H.D. and Fauci, A.S. (2020). Coronavirus infections-More than just the common cold. JAMA 323: 707-708. https://doi.org/10.1001/jama.2 020.0757

Prather, K.A., Wang, C.C. and Schooley, R.T. (2020). Reducing transmission of SARS-CoV-2. Science 6498: 1422-1424. https://doi.org/10.1126/science.abc6197

Worldometer (2020). Reported cases and deaths by country, territory, or conveyance. https://www.worldometers.info/ coronavirus/\#countries

Sanders, J.M., Monogue, M.L., Jodlowski, T.Z. and Cutrell, J.B. (2020). Pharmacologiec treatments for coronavirus disease 2019 (COVID-19): A review. JAMA 323: 1824 1836. https://doi.org/10.1001/jama.2020.6019

Setti, L., Passarini, F., De Gennaro, G., Barbieri, P., Grazia Perrone, M., Borelli, M., Palmisani, J., Di Gilio, A., Piscitelli, P. and Miani, A. (2020). Airborne transmission route of COVID-19: Why 2 meters/ 6 feet of interpersonal distance could not be enough. Int. J. Environ. Res. Public Health 17: 2932. https://doi.org/10.3390/ijer ph17082932

Shaman, J., Goldstein, E. and Lipsitch, M. (2011). Absolute humidity and pandemic versus epidemic influenza. Am. J. Epidemiol. 173: 127-135. https://doi.org/10.1093/aje/kw q347

Somsen, G.A., van Rijn, C., Kooij, S., Bem, R.A. and Bonn, D. (2020). Small droplet aerosols in poorly ventilated spaces and SARS-CoV-2 transmission. Lancet Respir. Med. 8: 658-659. https://doi.org/10.1016/S2213-2600(20) 30245-9

Suhaimi, N.F., Jalaludin, J. and Latif, M.T. (2020). Demystifying a possible relationship between COVID19, air quality and meteorological factors: Evidence from Kuala Lumpur, Malaysia. Aerosol Air Qual. Res. 20: 1520-1529. https://doi.org/10.4209/aaqr.2020.05.0218

Tamerius, J.D., Shaman, J., Alonso, W.J., Bloom-Feshbach,
K., Uejio, C.K., Comrie, A. and Viboud, C. (2013). Environmental predictors of seasonal influenza epidemics across temperate and tropical climates. PLoS Pathog. 9: 1003194. https://doi.org/10.1371/journal.ppat.1003194

Taylor, S. (2020, April 30). Why the fight against COVID-19 must include indoor air humidity. Building. https://buildi ng.ca/feature/why-the-fight-against-covid-19-must-includeindoor-air-humidity/

Tellier, R., Li, Y., Cowling, B.J. and Tang. J.W. (2019) Recognition of aerosol transmission of infectious agents: A commentary. BMC Infect. Dis. 19: 101. https://doi.org/ 10.1186/s12879-019-3707-y

van Doremalen, N., Bushmaker, T. and Munster, V.J. (2013). Stability of Middle East respiratory syn-drome coronavirus (MERS-CoV) under different environmental conditions. Eurosurveillance 18: 20590. https://doi.org/1 0.2807/1560-7917.es2013.18.38.20590

van Doremalen, N., Bushmaker, T., Morris, D.H., Holbrook, M.G., Gamble, A., Williamson, B.N., Tamin, A., Harcourt, J.L., Thornburg, N.J., Gerber, S.I., Lloyd-Smith, J.O., de Wit, E. and Munster, V.J. (2020). Aerosol and surface stability of SARS-CoV-2 as compared with SARS-CoV-1. N. Engl. J. Med. 382: 1564-1567. https://doi.org/10.1056/ NEJMc2004973

World Health Organization (WHO) (2004). Cumulative Number of Reported Probable Cases of Severe Acute Respiratory Syndrome (SARS). https://www.who.int/csr/ sars/country/table2004_04_21/en/

World Health Organization (WHO) (2020a). Coronavirus disease (COVID-19) pandemic. https://www.who.int/eme rgencies/diseases/novel-coronavirus-2019

World Health Organization (WHO) (2020b). Report of the WHO-China Joint Mission on Coronavirus Disease 2019 (COVID-19). World Health Organization, Geneva. https://www.who.int/docs/default-source/coronaviruse/w ho-chinajoint-mission-on-covid-19-final-report.pdf

Yao, M., Zhang, L., Ma, J. and Zhou, L. (2020). On airborne transmission and control of SARS-Cov-2. Sci. Total Environ. 731: 139178. https://doi.org/10.1016/j.scitotenv. 2020.139178

Yuan, J., Yun, H. and Lan, W. (2006). A climatologic investigation of the SARS-CoV outbreak in Beijing, China. Am. J. Infect. Control 34: 234-236. https://doi.org/ 10.1016/j.ajic.2005.12.006

Received for review, June 16, 2020

Revised, July 17, 2020 Accepted, July 21, 2020 